\title{
Major Retailing Logistics Management Mechanisms
}

\author{
Yan-Ling Wang ${ }^{1,2}$ \\ ${ }^{1}$ Zhejiang Wanli University, 315100 Ningbo, Zhejiang, P. R. China \\ ${ }^{2}$ Dalian Maritime University, 116026 Dalian, Liaoning, P. R. China \\ E-mail: yanling_wang1@yahoo.com.cn
}

Keywords: Logistics supply chain; optimized design mechanisms; operating management; fishery industry.

\begin{abstract}
Due to the emergence of the global economy and increased competition, many of the modern fishing companies have recognized that their fisheries rapid product introduction and service innovation to market the importance of supply chain management. To improve their competitiveness, many modern fishing companies have accepted supply chain management to improve organizational effectiveness and achievement of organizational objectives, increase customer value, better use of resources, and improve profitability. Consider adhere to enterprise operational efficiency to improve collaboration and client response in the modern fisheries management advocated by business partners, an additional thrust towards a successful competitive strategy. Supply chain management in the fisheries industry has become part of the agenda of the senior management of the fishery production and the retail industry. Appropriate mechanism to optimize fisheries logistics supply chain design and effective fisheries management method is a reference to the fisheries in this article the major retail logistics supply chain management. Soft computing technology based on the proposed new program, and effectively solve the problems by a variety of dynamic segment of the logistics supply chain of the fisheries of the major retail companies.
\end{abstract}

\section{Introduction}

Fisheries emerging global economy and increased competition led to many companies recognize that their fisheries and rapid product introduction and service innovation to market the importance of supply chain management. In order to improve their competitiveness, many companies in the fisheries industry has accepted the fisheries supply chain management to improve organizational effectiveness and achievement of organizational objectives, increase customer value, better use of resources, and improve profitability. Consider adhere to enterprise operational efficiency to improve collaboration and client response in the modern fisheries management advocated by business partners, an additional thrust towards a successful competitive strategy. Supply chain management in the fisheries industry has become part of the agenda of senior management in the manufacturing and retail sectors. Fisheries production and retail counterparts in the fisheries industry executives all know that successful coordination, integration and management of critical business processes, the entire members of the fisheries supply chain will ultimately determine the success of their competition. In the modern retail environment, fisheries, fisheries, retailers have to deal with domestic and global competition by traditional and non-traditional channels. In addition, managers are increasingly aware that they no longer compete fully self-governing entity in the fisheries industry. On the contrary, the competition between the fisheries supply chain. Also been driven by the increased interest of the fishing industry, supply chain management, frequently exchange large amounts of information between the chain participants, the purpose of coordination, information and communication technology development. Therefore, it is necessary to establish more effective and efficient fisheries supply chain business partners the opportunity of a joint approach. This is especially true in the National Fisheries retail supply chain, because the National Fisheries of the total retail sales of goods and increase the concerns of consumers, safety and environment-friendly production methods of the National Fisheries retail, shelf-life restrictions. The National Fisheries retail chains and networks play an important role to 
provide access to the market of fishery producers from developing countries, as well as local, regional and export markets. Fishing retailers look forward to beyond their organizational boundaries, resources and capacity of their fishing suppliers and customers of the assessment and integration, thereby creating greater value and competitive advantage, they may continue for some time. Fishing retailers not only to balance the return on assets, growth, inventory turns, but in its fisheries supply chain partners, to promote the demand to develop the strategic policy. For example, fisheries, retailers usually facing a major challenge when trying to balance fisheries supply and demand. In order to gain access to capacity, and reduce transportation costs, fisheries retailers must always be in style, color, size, number of the next few months locked, and then shipping arrangements to minimize transportation costs. While this minimizes the fisheries procurement and transportation costs, also reduces the response to place the success of fisheries fashion replenishment orders, and requested a reduced price of unsuccessful fishing fashion. National Fisheries retail competitiveness of industrial enterprises, small and large there will be innovation and reduce costs, and more responsive to consumer demand, the retail system in the national fisheries. This can help fisheries supply chain management in national Fisheries retail system. Simply ignored the National Fisheries retail supply chain to increase future losses or business interruption potential and possibilities. In recent years have seen the concentration of the increasing globalization of the market and fishing companies on their core competitiveness. Individual companies to compete in the fishing industry, is no longer independent fishing entities with unique brand names, but as part of the fishery logistics supply chain. An increasing number of fishing companies have begun to realize the importance of strategic planning, the design of the control and fishery logistics supply chain as a whole. Therefore, the ultimate success of the fishing companies will depend on the intricate network of business relationships between its fisheries management capabilities, integration and coordination of the logistics supply chain members to participate in the value of the process, more and more independent fishing companies in the legal and economic part of the entire fishery logistics supply chain. Because of the need to increase cooperation between the fishing companies and fisheries co-ordination of the logistical decision-making in the interest of the fisheries supply chain management field is the growth of recent scholars and practitioners. In the supply chain management of the fisheries industry in the planning, implementation and control the operation of the fisheries supply chain in an effective manner. Covers all fishery raw materials, work processes, inventory, supply chain management in the fisheries industry and the movement of goods and storage of finished fishery point of origin to point of consumption. Part of the fisheries supply chain management planning process aimed at finding the best of the fisheries supply chain configuration. In addition to the general location of the facilities is set, must also consider other areas, such as fisheries procurement, production, inventory, distribution, routing. Therefore, a major problem in fisheries logistics supply chain management is to find a suitable mechanism for optimization of design, when a fishing company decided to open and operate their fisheries warehouse and cross-pier, spend a huge amount of funds to open their best sets of cross-terminals and other fisheries of the warehouse logistics supply chain management, the main problem is the effective management of fisheries logistics supply chain is by individual fishing companies has been opened and operated fishing companies, fisheries warehouse, and to achieve the overall minimum cost control The process cross-pier [1]. Programs, such as vendor managed inventory and continuous replenishment planning, the optimization of the logistics supply chain design and management methods. However, when a number of constraints and variables, the program processing time is very long, so as not suitable for dynamic applications. Focus on soft computing optimization methods Therefore, we will learn the appropriate fisheries logistics supply chain management to optimize the management of fisheries logistics supply chain design mechanisms and effective fisheries fisheries major retail companies logistics supply chain in the following management problems modeled based. Soft computing technology based on the proposed new program, and effectively solve the problems by a variety of dynamic segment of the fisheries major retail logistics supply chain. 


\section{Problem Representation}

Similar to other logistics and supply chain processes, fisheries logistics supply chain to be called as an integrated system, synchronization, access to the fishery raw materials and parts to a series of interrelated fisheries business processes: (1), (2) transformation of the raw materials of these fisheries and section to enter the fishery finished, (3) the added value of these aquatic products, (4) distribution, and the promotion of these fishery products or fishery retailers or customers, (5) promote the exchange of information, the fisheries business entity (such as suppliers, manufacturers, distributors, third party logistics providers and retailers in the fishery). Its main purpose is to improve operational efficiency, profitability and competitiveness of the fisheries and the status of the fisheries supply chain partners. Fisheries commodities that it can characterize the forward and backward flow and information flow. Fisheries logistics supply chain entities are highly interdependent, and to improve fisheries objectives, such as cost minimization, quality assurance, on-time delivery of supply chain performance. Therefore, any entity in the fisheries supply chain performance depends on the performance of others within the range of their ability to coordinate the fisheries supply chain activities [1] - [5]. Unlike traditional logistics, fisheries logistics supply chain management involves the independent management of the fishing companies to seek their own profit-maximizing co-ordination. Effective fisheries logistics supply chain management needs of members of the various channels, including fisheries coordination between retailers, manufacturers and intermediaries. Fisheries logistics supply chain management a major problem is to find a suitable design of the optimization of fisheries, fishing companies decided to open and operate their fisheries warehouse and cross-pier, spend a huge amount of funds to open it the best set of fisheries cross-docks and warehouses, such as the main problems of the fisheries supply chain management is effective fisheries logistics supply chain is a fishing company has opened and operated by individual fishing companies control the process in order to achieve the overall minimum cost, and its fisheries The operating management of warehouse and cross-pier. In addition, the mechanism must ensure that everyone in the fishing companies, will reach the same profit at least in the application before the mechanism of the existing supply chain partnership. In the following, we will consider the Fisheries logistics supply chain optimization design mechanisms and effective management of fisheries in the country, mainly for the country's distribution management of fisheries products retailing company. Retail companies in the country's fisheries, fishery and logistics manager must decide what is the quality objectives and control methods of aquatic resources of whether the organization in fishery products or processes. In a sense, a major commitment to fishing companies decided to opening and use of fisheries warehouse and cross-pier, spend a huge amount of funds to open it the best set of fishing piers and warehouses, its present and future assets. Such decisions, the objective function is to minimize the total cost, including fixed costs to open the fisheries warehouse and cross dock, transportation costs from the fishery warehouse cross dock fishery products, fishery products cross and cost terminals to meet the needs of customers, it can be expressed for the following combination of multi-constraint optimization problems in other sectors of the logistics supply chain management [1] - [5]

$$
\min \left\{\begin{array}{c}
C_{\text {total }}= \\
F_{\text {cross-docks }}+F_{\text {warehouses }} \\
+V_{\text {cross-docks-customers }}+U_{\text {warehouses-ross-docks }}
\end{array}\right\}
$$

subject to

$$
\begin{gathered}
F_{\text {cross-docks }}=\sum_{j=1}^{J} f_{\text {cross-dock } j} a_{j} \\
F_{\text {warehouses }}=\sum_{i=1}^{I} f_{\text {warehouses } i} b_{i} \\
V_{\text {cross-docks-customers }}=\sum_{j=1}^{J} \sum_{l=1}^{L} \sum_{p=1}^{P} v_{j l p} c_{j l p} \\
U_{\text {warehouses-cross-docks }}=\sum_{i=1}^{I} \sum_{j=1}^{J} \sum_{p=1}^{P} u_{i j p} d_{i j p}
\end{gathered}
$$




$$
\begin{aligned}
& \sum_{j} c_{j l p}=1 \quad \forall l \text { and } p \\
& \sum_{i} d_{i j p}=a_{j} \quad \forall j \text { and } p \\
& \sum_{i} \sum_{p} g_{l p} c_{j l p} \leq m_{j} \quad \forall j \\
& \sum_{j} \sum_{p} m_{l p} d_{i j l} \leq n_{l} \quad \forall l \\
& c_{j l p}=\left\{\begin{array}{c}
1 \quad \text { if the } l \text { th fishery customer zone is assigned to } \\
\text { the } j \text { th fishery cross - dock for the } p \text { th fishery product, } \\
0 \quad \text { otherwise, }
\end{array}\right. \\
& d_{i j l}=\left\{\begin{array}{c}
1 \quad \text { if the } j \text { th fishery cross - dock is assigned to } \\
\text { the } i \text { th fishery warehouse for the } p \text { th fishery product, } \\
0 \quad \text { otherwise, }
\end{array}\right. \\
& a_{j}=\left\{\begin{array}{cc}
1 & \text { if the } j \text { th fishery cross - dock is open, } \\
0 & \text { otherwise }
\end{array}\right. \\
& b_{i}=\left\{\begin{array}{cc}
1 & \text { if the } i \text { th fishery warehouse is open, } \\
0 & \text { otherwise, }
\end{array}\right.
\end{aligned}
$$

where $C_{\text {Total }}, f_{\text {cross-dock } j}, f_{\text {warehouses } i}, v_{j l p}, u_{i j p}, g_{l p}, m_{j}, n_{j}$, respectively, denotes, the total cost to be minimized, the fixed operating cost to operate/open the ${ }^{j \text { th }}$ fishery cross-dock, the fixed operating cost to operate/open the $i$ th fishery warehouse, the cost to supply the $p$ th fishery product from the ${ }^{j \text { th }}$ fishery cross-dock which would be used by the lth customer zone, the cost to transport the $p$ th fishery product from the $i$ th fishery warehouse to the ${ }^{j \text { th }}$ fishery cross-dock, the demand from the $l$ th fishery customer zone for the ${ }^{p \text { th }}$ fishery product, the capacity of the ${ }^{j \text { th }}$ fishery cross-dock to handle product families, the capacity of the ith fishery warehouse to handle product families. The first constraint (6) ensure that each demand point (customer) are satisfied for all fishery products. (7) constraints limit the cross-dock to be assigned to open fisheries warehouse. Constraint (9) Fisheries warehouse capacity constraints, to ensure that the the fishery cross-dock capacity limit constraints (8). The implementation of the constraint (10) - (13) the limit of binary decision variables. Fishing company has opened a run fisheries warehouse and cross-pier, it had to deal with in place, the fishing facilities they operate. In other industries, such behavior is usually referred to as a business decision, or operate the infrastructure. Fishery management decision-making objective function is the total cost includes warehouse transportation product family generated to minimize transportation costs, transfer costs to cross-dock warehouse ships from the series of fishery products and distribution costs, fishery boat product lines from the inter-terminal client area, it can be expressed for multi-constraint combination fishing operations optimization problem [1] - [5]. Therefore, when we want to the AFORE predict the best set of cross-docks and warehouses were open, the optimization is the most important thing and the problem of processing time is negligible. Therefore, all possible combinations of a cross-docks and warehouses are open, should be considered and compared in order to choose the best one. After, the company has opened a warehouse and cross-Pier, a number of constraints and variables is large, while the two sides of the constraints and variables are dynamic, so the actual multi-constraint combinatorial optimization plan should consider it not only the minimum cost of the overall operation and management of fisheries logistics supply chain processes, but there is no need to be addressed too long. Heuristic soft computing techniques, can provide near optimal solutions to combinatorial optimization problem. Heuristic soft computing techniques have been applied to a single multi-objective optimization problem of the majority. As the configuration of a chromosome, if the feasibility of the flow of each individual fishery products and cross-pier and warehouse location allocation objective function value was regarded as the fitness function of chromosomes, to determine the product flows to the lowest-cost allocation of cross-docks and warehouses similar to find the cause of the population in the lowest energy state, including a potential solution to explore the 
structure of open cross-docks and warehouses in all product flow distribution and the potential configuration. Therefore, an appropriate optimization of the design heuristic genetic algorithm-based approach, can propose to solve the chain management and processing at large portfolio of fisheries logistics supply a short time. In the proposed genetic algorithm-based approach, any potential solution can be expressed as the initial population of chromosomes. For simple implementation, the initial configuration and objective function value is randomly generated, configure the warehouse and cross-Pier was opened across terminals and cross-Terminal distribution, distribution warehouse from the factory to the customer's product line, the total the calculation of the cost objective function, the feasibility of the initial solution is selected. Allocated to it a fitness function. Initial population over several generations of the process is improved. In each generation, new chromosomes from a variety of genetic operators, crossover and mutation, such as. Considering the standard of their fitness function for the future population of chromosomes is selected from the previous population. This process is repeated until the termination condition. In this paper, the heuristic genetic algorithm terminates feel satisfied when at least one of the following conditions: (a) from the beginning of last year to improve and if that fails, to provide better and more iterative solution, or (b) if reaches the preset maximum iteration value.

\section{Summary}

Suitable for optimizing the design of the logistics supply chain mechanisms and effective management methods, major retail logistics supply chain management with reference to this article.

\section{Acknowledgments}

This work was supported in part by the National Soft Science Foundation of China (No. 2010GXS5D214), the Education of Ministry Humanities Social Sciences Research Project (No. 11YJA630135), the Science Foundation of Zhejiang Wanli University.

\section{References}

[1] D. Simchi-Levi, P. Kaminsky and E. Simchi-Levi, Managing the Supply Chain - The Definitive Guide for the Business Professional, New York: McGraw-Hill, 2004.

[2] D. Simchi-Levi, P. Kaminski, Designing and managing the supply chain-concepts, strategies and case studies, New Jersey: McGraw-Hill, 2006.

[3] M. G. Sylvia Thompson, M. T. Morrissey. "Seafood Traceability in the United States: Current Trends, System Design, and Potential Applications", Comprehensive Reviews in Food Science and Food Safety, pp. 1-7, vol. 4, no. 1, 2005.

[4] K. Kogan, A. Herbon, "A supply chain under limited-time promotion: The effect of customer sensitivity," European Journal of Operational Research, Vol. 188, pp. 273-292, 2008.

[5] G. Cachon, R. Swinney, "Purchasing, Pricing, and Quick Response in the Presence of Strategic Customers," Management Science, Vol. 55, No. 3, pp. 497-511, 2009. 